\title{
Combination of Xylanase and Debranching Enzymes Specific for Wheat Arabinoxylan Improve the Growth Performance and Gut Health of Broilers
}

Zhao Lei, Yuxin Shao, Xiaonan Yin, Dafei Yin, Yuming Guo, Jianmin Yuan

State Key Laboratory of Animal Nutrition, College of Animal Science and Technology,

China Agricultural University, 2 Yuanmingyuan West Road, Beijing, 100193, PR China

Table 8.The FITC Concentration of Ileum of Broilers on d $36^{*}(30 \mathrm{~min})$

\begin{tabular}{cc}
\hline Treatment $^{a}$ & FITC $^{b}(\mathrm{ng} / \mathrm{ml})$ \\
\hline $\mathrm{CT}$ & $3335.61 \pm 59.15^{\mathrm{ab}}$ \\
$\mathrm{X}$ & $3255.61 \pm 51.22^{\mathrm{ab}}$ \\
$\mathrm{X}+\mathrm{A}$ & $3191.37 \pm 38.27^{\mathrm{a}}$ \\
$\mathrm{X}+\mathrm{F}$ & $3183.98 \pm 43.29^{\mathrm{b}}$ \\
$\mathrm{X}+\mathrm{A}+\mathrm{F}$ & $3165.31 \pm 46.51^{\mathrm{b}}$ \\
$\mathrm{SEM}$ & 23.39 \\
$P$-value & 0.029 \\
\hline
\end{tabular}

*Values with the same superscript letter within column are not significantly different at $P<0.05$.

${ }^{a} \mathrm{CT}$ : control; X: xylanase; A: ABF; F: FAE. Data are means for 5 replicates of 10 chickens per group. ${ }^{b}$ fluorescein isothiocyanate. 